\title{
ROS1 Gene Rearrangement Positive Non-small cell Lung Cancer
}

\author{
Dinesh Chandra Doval ${ }^{1,2}$, Rupal Sinha ${ }^{2}$, Moushumi Suryavanshi ${ }^{3}$, Kumardeep Dutta Choudhury ${ }^{1}$, Ajay \\ Sharma ${ }^{1}$, PS Choudhury ${ }^{4}$, Anurag Mehta ${ }^{3}$
}

Departments of ${ }^{1}$ Medical Oncology, ${ }^{2}$ Research, ${ }^{3}$ Laboratory Services, ${ }^{4}$ Nuclear Medicine; Rajiv Gandhi Cancer Institute \& Research Centre, Delhi, India.

\begin{abstract}
Corresponding Author:
Dr. Dinesh Chandra Doval

Email: dcdoval@gmail.com

This is an Open Access article distributed under the terms of the Creative Commons Attribution License (creativecommons.org) licenses/by/3.0).
\end{abstract}

Received

Accepted

Published

August 20, 2016

December 6, 2016

January 10, 2017

\begin{abstract}
Background: Cancer treatment has witnessed a paradigm shift due to identification of driver mutations at the genetic level with cognate targeted therapies to negate the same. Development of acquired resistance is however, inevitable. Case Report: We present the case of a non-small cell lung (NSCLC) cancer patient with ROS1 gene rearrangement who developed acquired resistance to crizotinib. Conclusion: This case brings into light the rare NSCLC patient with ROS1 gene rearrangement in Indian population.
\end{abstract}

Keywords: Crizotinib, Gene Rearrangement, Mutation, Non-Small-Cell Lung Carcinoma.

\section{Introduction}

Lung cancer is the most common cause of cancer related mortality and is usually diagnosed as advanced cancer with more than half being adenocarcinomas [1]. Of these, around $1-2 \%$ cases have exhibited $\mathrm{C}$-ros oncogene 1 rearrangement which is druggable by crizotinib [2]. ROS1 gene is exclusive to other oncogenes including epidermal growth factor receptor (EGFR), anaplastic lymphoma kinase (ALK) and Kirsten rat sarcoma viral gene homolog (KRAS) [3]. Resistance to targeted therapy can develop rapidly.

\section{Case Report}

A 47 year old female presented in December 2014 with complaints of chest pain, backache, hoarseness of voice, cough with expectoration, loss of weight and appetite of 2 months duration. CT thorax was suggestive of right hilar bronchogenic carcinoma with multiple vertebral metastases. Clinically, she had bilateral enlarged supraclavicular nodes. PET CT was suggestive of metabolically active right lung lesion with lymph nodal, adrenal, liver, bony and right adnexal involvement. Left cervical lymph-node biopsy was reported as TTF-1 positive metastatic adenocarcinoma. She was administered pemetrexed and cisplatinum based chemotherapy and injection zoledronic acid. Immunohistochemistry (IHC) for ALK-1 protein expression was negative and she did not have any epidermal growth factor receptor (EGFR) mutation. Post third cycle of chemotherapy, her PET CT showed partial response to treatment in different sites [Fig.1]. She was continued on chemotherapy for further 3 cycles.

PET CT evaluation in May 2015 was suggestive of progressive disease in bones. She also complained of headache. A MRI brain showed bony lesion with no demonstrable enhancing parenchymal/ meningeal lesion in brain. She received external beam radiotherapy to lumbar spine (L2) and right pubis to a dose of $30 \mathrm{~Gy} / 15 \#$ and $20 \mathrm{~Gy} / 5 \#$ to right knee on $6 \mathrm{MV}$ Linac. She was subsequently started on injection denosumab and oral tarceva $150 \mathrm{mg}$. She was admitted with complaints of progressive breathlessness and later developed stridor. 
PET CT in June 2015 was suggestive of overall metabolically active progressive disease. In the meantime, the biomarker testing was extended to C-Met amplification and ROS1 rearrangement and fortunately, the latter tested positive [Fig.2]. She was administered oral crizotinib $250 \mathrm{mg}$ twice daily and was continued for 2 months. PET CT showed significant reduction in the size of the mass lesion. Four months later (October 2015), she complained of severe headache, nausea, and blurring of vision, slurred speech. MRI brain showed multiple supra and infratentorial brain lesion suggestive of central nervous system (CNS) metastases along with occipital bony lesion. Patient was started on CNS RT. A PET CT again showed progressive disease.

Patient was keen to get enrolled into a clinical trial with carbozantinib and went to Singapore where she was evaluated and also found to have granulomatous tubercular lesion in the lung which was an exclusion criterion for the referenced study. She was put on ATT and came back to India for further management. In November 2015, she received external beam radiotherapy to posterior fossa to a dose of $9 \mathrm{~Gy} / 3 \#$ followed by $30 \mathrm{~Gy} / 10 \#$ to whole brain on $6 \mathrm{MV}$ Linac. She succumbed to the disease in December 2015. The time from diagnosis to death was 12 months.

\section{Discussion}

Lung cancer remains a leading cause of cancer deaths worldwide. Patients with NSCLC account for about $80 \%$ cases and are a matter of investigation for the development of molecular based targeted therapies for appropriate management of the disease [4]. A relatively new player in NSCLC is the C-ros oncogene 1(ROS1) fusion gene reported in about $1 \%$ patients with NSCLC [5]. Frequencies of ROS1 fusions in NSCLC have been studied in various populations including Chinese, Japanese, Asian and non-Asian groups [6].

ROS1 is an oncogene product of the avian sarcoma virus UR2 and its dys-regulation may

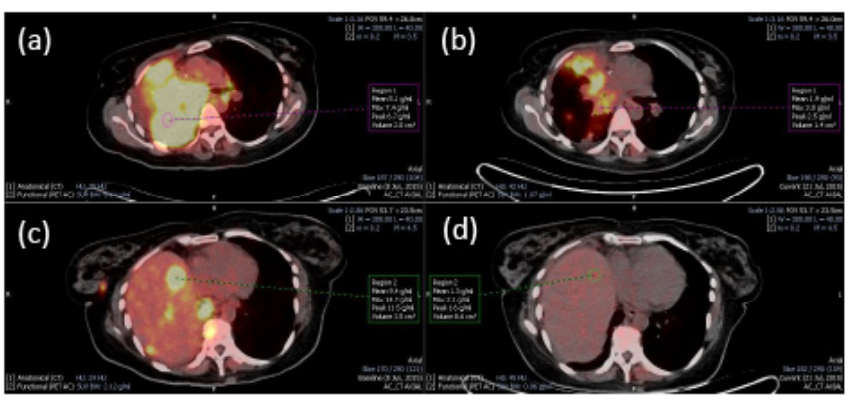

Fig.1(a\&b): PET-CT images of right lung mass showing good partial response pre and post treatment with crizotinib. (c\&d): Liver and bony lesions showing significant response to therapy (pre and post).

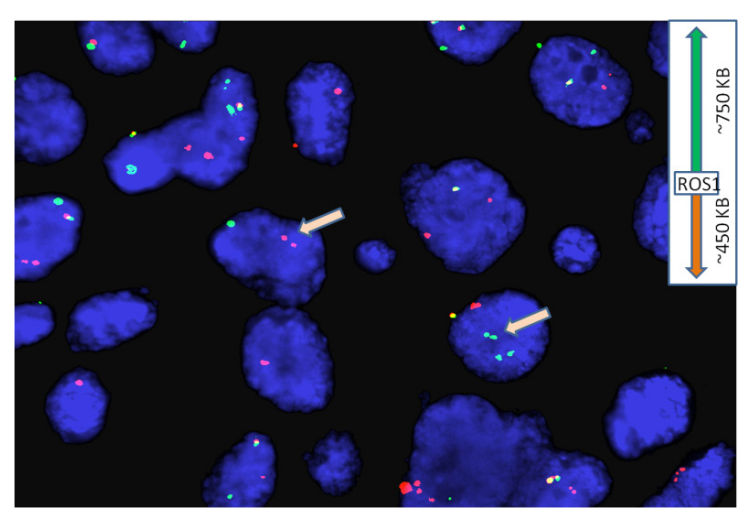

Fig.2: Paraffin embedded section showing ROS1 translocation indicated by one orange/green fusion signal (non-rearranged), and one orange and one separate green signal indicating the translocation (inset: SPEC ROS1 probe map).

occur due to ROS1 gene mutations, overexpression or fusion which further leads to the activation of downstream signaling of various oncogenic pathways. Various fusion variants of ROS1 gene involving different chromosomal translocations have been described in NSCLC [7]. Due to $49 \%$ amino acid sequence homology of ROS1 with EML4-ALK, treatment with crizotinib in this category also has shown high antitumor activity. The overall response rates have been observed to be as high as $56 \%$ [2]. Development of resistance with the use of targeted therapies remains a cause of concern till today. Also, ROS1 tyrosine kinase mutations, EGFR activation and epithelial to mesenchymal transition may be linked to the 
development of resistance with the use of crizotinib. Newer second line targeted therapies including foretinib, ceritinib, alectinib, lorlatinib, brigatinib, entrectinib, etc. may be utilized for managing this condition [8-10].

\section{Conclusion}

Overall, the present report brings to light the case of a NSCLC patient with ROS1 gene rearrangement and is probably the first one from the Indian population. Targeted therapy was utilized but acquired resistance due to its use remains inevitable.

Contributors: DCD: Study conception and critical revision; RS: Manuscript revision; MS, AM.: Molecular data; KDC, AS: Critical revision. RS will act as guarantor. All authors approved the final version of the paper.

Funding: None; Competing interests: None stated.

\section{References}

1. Inamura $\mathrm{K}$, Ninomiya $\mathrm{H}$, Ishikawa $\mathrm{Y}$, Matsubara $\mathrm{O}$. Is the epidermal growth factor receptor status in lung cancers reflected in clinicopathologic features? Arch Pathol Lab Med. 2010;134:66-72.

2. Ou SI, Bang Y, Camidge DR, Riely GJ, Salgia R, Shapiro G. Efficacy and safety of crizotinib in patients with advanced ROS1-rearranged non-small cell lung cancer (NSCLC). J Clin Oncol. 2013;31(suppl): abstr 8032.
3. Wu S, Wang J2, Zhou L3, Su D3, Liu Y1, Liang X1, Zhang S2, Zeng X1. Clinicopathological characteristics and outcomes of ROS1-rearranged patients with lung adenocarcinoma without EGFR, KRAS mutations and ALK rearrangements. Thorac Cancer. 2015;6(4):413-420.

4. Shames DS, Wistuba II. The evolving genomic classification of lung cancer. J Pathol. 2014;232(2):121133.

5. Gainor JF, Shaw AT. Novel targets in non-small cell lung cancer: ROS1 and RET fusions. Oncologist. 2013;18(7):865-875.

6. Rikova K, Guo A, Zeng Q, Possemato A, Yu J, Haack $\mathrm{H}$, et al. Global survey of phosphotyrosine signaling identifies oncogenic kinases in lung cancer. Cell. 2007;131(6):1190-1203.

7. Gu TL, Deng X, Huang F, Tucker M, Crosby K, Rimkunas $\mathrm{V}$, et al. Survey of tyrosine kinase signaling reveals ROS kinase fusions in human cholangiocarcinoma. PLoS One. 2011;6(1):e15640.

8. Shaw AT, Friboulet L, Leshchiner I, Gainor JF, Bergqvist $\mathrm{S}$, Brooun A, et al. Resensitization to Crizotinib by the Lorlatinib ALK Resistance Mutation L1198F. N Engl J Med. 2016;374(1):54-61.

9. Rolfo C, Ruiz R, Giovannetti E, Gil-Bazo I, Russo A, Passiglia F, et al. Entrectinib: a potent new TRK, ROS1, and ALK inhibitor. Expert Opin Investig Drugs. 2015;24(11):1493-1500.

10. Sullivan I, Planchard D. ALK inhibitors in non-small cell lung cancer: the latest evidence and developments. Ther Adv Med Oncol. 2016;8(1):32-47. 